\title{
Effects of Barnacle Encrustation on the Swimming Behaviour, Energetics, Morphometry, and Drag Coefficient of the Scallop Chlamys Hastata
}

Deborah Anne Donovan

Western Washington University, deborah.donovan@wwu.edu

Brian L. Bingham

Western Washington University, brian.bingham@wwu.edu

Milton From

Western Washington University

Abby F. Fleisch

Northwestern University

Eli S. Loomis

Western Washington University

Follow this and additional works at: https://cedar.wwu.edu/esci_facpubs

Part of the Environmental Sciences Commons

\section{Recommended Citation}

Donovan, Deborah Anne; Bingham, Brian L.; From, Milton; Fleisch, Abby F.; and Loomis, Eli S., "Effects of Barnacle Encrustation on the Swimming Behaviour, Energetics, Morphometry, and Drag Coefficient of the Scallop Chlamys Hastata" (2003). Environmental Sciences Faculty and Staff Publications. 3.

https://cedar.wwu.edu/esci_facpubs/3 


\title{
Effects of barnacle encrustation on the swimming behaviour, energetics, morphometry, and drag coefficient of the scallop Chlamys hastata
}

\author{
Deborah A. Donovan*`, Brian L. Bingham ${ }^{\dagger}$, Milton From $^{\ddagger}$, Abby F. Fleisch ${ }^{\jmath}$ and Eli S. Loomis* \\ *Department of Biology, MS 9160, Western Washington University, Bellingham, WA 98225, USA. 'Department of Environmental \\ Sciences, MS 9081, Western Washington University, Bellingham, WA 98225, USA. ${ }^{\ddagger}$ Department of Physics and Astronomy, MS 9164, \\ Western Washington University, Bellingham, WA 98225, USA. 'Department of Biochemistry, Molecular Biology \& Cell Biology, \\ Northwestern University, Evanston, IL 60208, USA.

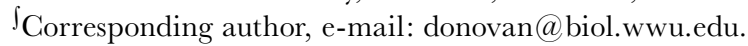

\begin{abstract}
Barnacle encrustation negatively influenced every aspect of swimming in the scallop Chlamys hastata measured in this study. Scallops swam significantly longer, travelled further and attained greater elevation once epibiotic barnacles had been removed. Shell morphometry of barnacle-encrusted scallops was similar to shells of unencrusted scallops. Specifically, shell length was positively allometric with shell height and shell mass was negatively allometric. However, adductor muscle mass scaled isometrically to shell height, in contrast to unencrusted scallops. In the laboratory, the drag coefficient $\left(\mathrm{C}_{\mathrm{d}}\right)$ of barnacle-encrusted scallops decreased after barnacle removal, in contrast to sponge-encrusted scallops in which no decrease in $\mathrm{C}_{\mathrm{d}}$ was detected when the sponge was removed from the scallop's valves. Furthermore, scallops swimming with barnacle encrustation required more energy than did unencrusted scallops. Although there was no significant difference in aerobic energy expenditure between swimming barnacle-encrusted and unencrusted scallops, differences in anaerobic energy expenditure were detected. Specifically, barnacle-encrusted scallops required more arginine phosphate than unencrusted scallops to swim to exhaustion although octopine levels were similar. Thus, barnacle encrustation dramatically decreased a scallop's ability to swim, partly by increasing the drag coefficient experienced by the scallop and the energy required for swimming.
\end{abstract}

\section{INTRODUCTION}

Scallops worldwide are associated with various epibionts. The scallop-sponge relationship has garnered the most attention and is generally considered a mutualism, in which the scallop benefits because the sponge interferes with adhesion of predatory sea-star tubefeet (Bloom, 1975; Forester, 1979; Pitcher \& Butler, 1987), camouflages the scallop from predators (Pitcher \& Butler, 1987), or forms a physical barrier around byssal openings so that sea-stars are unable to insert digestive membranes (Forester, 1979). The sponge purportedly benefits from the association by avoiding predation as the scallop swims away from sponge predators (Bloom, 1975), by gathering nutrients from the scallop's inhalent current (Forester, 1979), or by being cleared of sediment when the scallop swims or spontaneously claps its valves (Burns \& Bingham, 2002).

Donovan et al. (2002) showed that encrustation by the sponges Mycale adhaerens Lambe and Myxilla incrustans Esper does not dramatically interfere with swimming in the scallop Chlamys hastata Sowerby. Energy expended during swimming and swimming distance and height were not significantly different between scallops with and without sponge encrustation. However, scallops without sponge encrustation remained swimming for a slightly longer period of time, possibly increasing the effectiveness of escape swims in their current-swept habitat. In general though, the impact of sponge encrustation on the ability of C. hastata to swim was minimal.

Scallops are often found associated with other encrusting epibionts such as barnacles, polychaete worms, bryozoans, tunicates, and algae. The effects of these epibionts are less well understood and may be more dramatic than the effects of sponges. For example, Gonzalez et al. (2001) describe an event in which two million Argopecten purpuratus Lamarck were stranded on a beach in northern Chile following a storm. The authors suggested that epiphytic algae contributed to the event since stranded individuals were of larger size-classes with substantial algal encrustations. They proposed that drag on the large surface area of the algae prevented the scallops from escaping the strong water movements.

Chlamys hastata are sometimes associated with large balanoid barnacles (Figure 1) and they coexist with various barnacle species throughout their range (southern Alaska to southern California). These barnacles can be so large the scallop is incapable of swimming, obviously impairing the scallop's ability to move about. When encrusted with smaller barnacles, scallops may be able to swim but often list to one side or do not swim as effectively. Such encrustation could make scallops more susceptible to predators since many scallops swim to avoid predation (Stephens \& 
Boyle, 1978; Peterson et al., 1982). However, scallops also swim for other reasons such as to position themselves in a better habitat (Moore \& Marshall, 1967; Hamilton \& Koch, 1996) or to migrate (Morton, 1980). Thus, barnacle encrustation could affect scallops in a variety of ways.

Scallops swim by clapping their shell valves together such that jets of water are directed past both sides of the hinge, propelling the scallop forward in a hinge-hindmost position (Moore \& Trueman, 1971). The forces acting on swimming scallops have been studied in some detail (Gould, 1971; Moore \& Trueman, 1971; Morton, 1980; Dadswell \& Weihs, 1990; Millward \& Whyte, 1992; Cheng \& DeMont, 1996a,b; Cheng et al., 1996). To remain swimming, scallops must produce enough lift to balance the force of gravity; lift can be generated by the hydrodynamic characteristics of the scallop shell as well as the downward component of the jet propulsion. Besides lift, enough propulsive thrust must be generated to overcome drag and to propel the scallop forward through the water. It is likely that barnacles affect both lift and drag experienced by swimming scallops. Relative to clean scallops, barnacle-encrusted individuals could have higher drag due to the size or shape of the barnacle protruding off the shell. In addition, the ability to generate lift may be compromised by the protruding barnacle which would alter the shape of the shell, and more lift would be needed to compensate for the increased mass.

The purpose of this study was to determine the extent to which barnacle encrustation affects the swimming ability of Chlamys hastata. The effects of encrustation on scallop swimming behaviour, morphometry, drag coefficient, and energy expenditure were investigated. This study was an extension of similar work investigating the effects of sponge encrustation on C. hastata (Donovan et al., 2002).

\section{MATERIALS AND METHODS}

\section{Experimental animals}

Chlamys hastata with encrusting barnacles (Balanus spp.) were collected by SCUBA divers near Shannon Point Marine Center, Anacortes, WA. The animals were held in tanks with continuously flowing seawater at ambient temperature (approximately $9^{\circ} \mathrm{C}$ ) and salinity (approximately $30 \mathrm{psu}$ ). The tanks were exposed to an ambient light regime but were never in direct sunlight.

\section{Swimming behaviour}

To measure the swimming response of $C$. hastata with epibiotic barnacles, scallops $(\mathrm{N}=25)$ were placed individually in a $2.5-\mathrm{m}$ diameter outdoor tank filled with seawater to a depth of $85 \mathrm{~cm}$. The bottom of the tank was marked with black tape to form a grid of $30 \times 30 \mathrm{~cm}$ squares. After a 10 min acclimation period, a predatory sea-star (Pycnopodia helianthoides Brandt) was placed next to the scallop. Contact with the seastar tube feet stimulated swimming in the scallop. A viewer on an elevated platform observed the path of the scallop and recorded it on a scale drawing of the tank and grid. The elevation in the water column that the scallop attained was determined by an observer

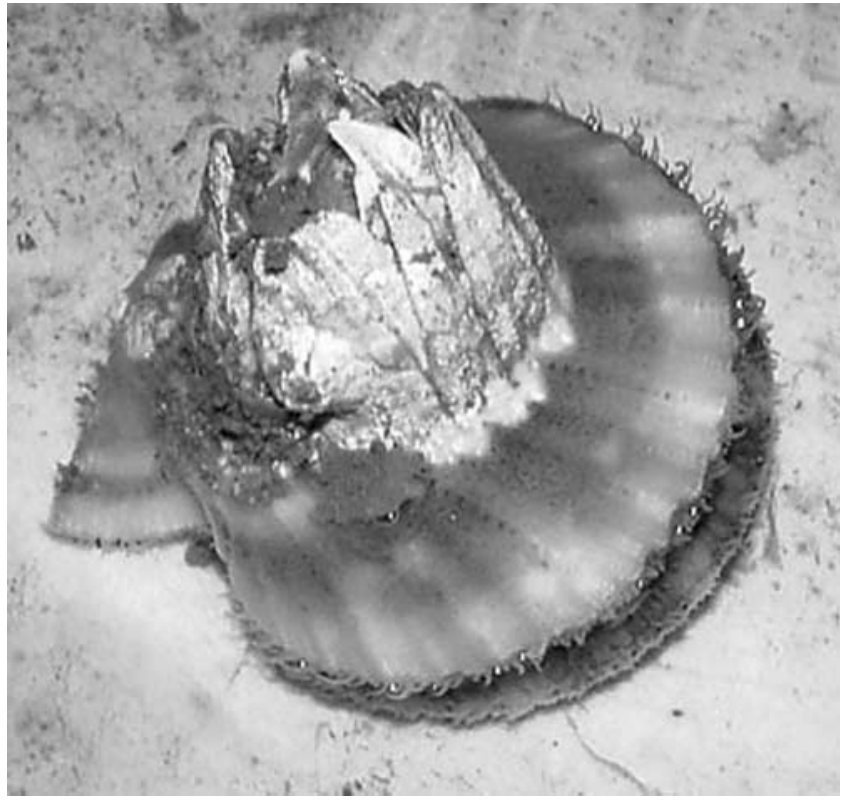

Figure 1. Chlamys hastata encrusted with a large balanoid barnacle.

watching through a port in the side of the tank. The total duration of the escape swimming was also measured.

Each C. hastata was induced to swim three times with 10 min of rest between trials. The duration and height of each swimming response were recorded. When the three trials had been completed, the scallop and its epibionts were blotted dry and weighed. The barnacles were then removed from the valve and the scallop was reweighed.

After at least $24 \mathrm{~h}$ [a period that has been used to allow scallops to recover after swimming in other studies (e.g. Thomas \& Gruffydd, 1971; Donovan et al., 2002)], the scallop was again placed in the outside tank and induced to swim three times, again with 10 min rest periods between swimming bouts. When all swimming trials were completed, the sheets with the swimming paths were digitally photographed and the files were opened in the Bioscan Optimas image analysis software program. The paths were traced to determine the total horizontal distance the C. hastata travelled in their swimming bouts.

To compare movement of the C. hastata with and without epibiotic barnacles, the results of the trials with barnacles were averaged to give a single swimming time, height and distance for each scallop. The results of the second series of trials were also averaged to give the swimming time, height and distance for the same scallops without barnacles. The results for each measure were compared with paired $t$-tests.

Since valve-clapping frequency was difficult to discern in the large tank, barnacle-encrusted scallops $(\mathrm{N}=10)$ were induced to swim in a smaller tank $(153 \times 69 \mathrm{~cm}, 30 \mathrm{~cm}$ depth). The scallops were stimulated to swim by touching their mantles with a $P$. helianthoides. Two observers timed each swim and counted the number of valve claps during the episode. This was repeated after a $10 \mathrm{~min}$ rest period. An average clap frequency for each scallop (claps $\min ^{-1}$ ) was determined from the four measurements. The barnacles were removed and, after a four hour rest period, the scallops were again induced to swim. An average clap frequency was determined without barnacle encrustation. Average 


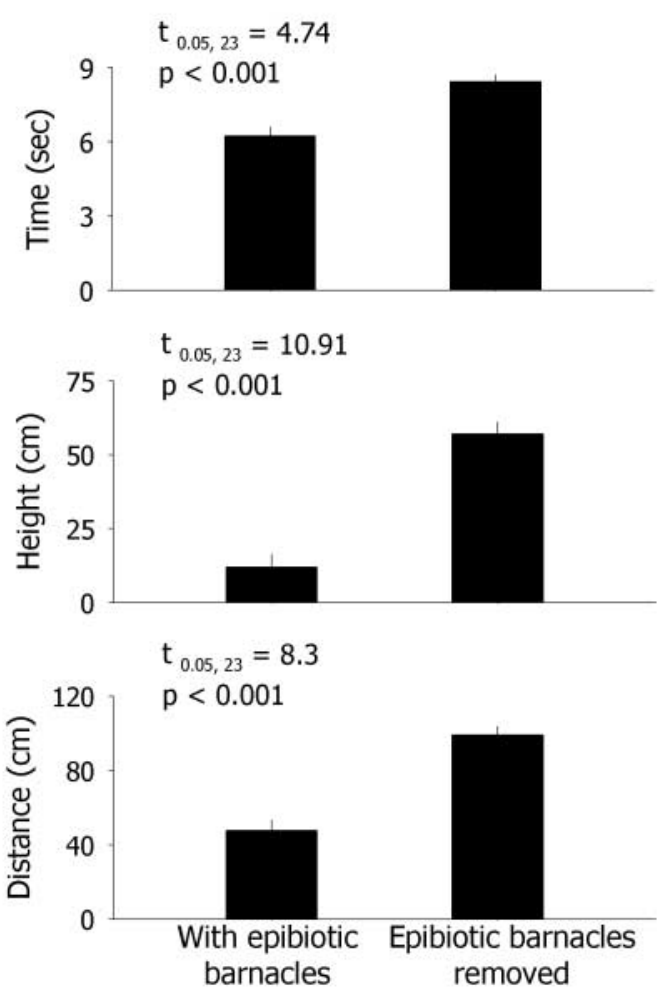

Figure 2. Swimming time, swimming height, and swimming distance of scallops with barnacle encrustation and after the barnacles had been removed. Error bars represent SE.

frequencies before and after barnacle removal were compared using a paired $t$-test.

\section{Scallop morphometry}

To determine the effect of barnacle encrustation on shell size and shape, barnacle-encrusted scallops $(\mathrm{N}=16)$ were collected and transferred to Western Washington University, Bellingham, WA where they were held in aerated seawater at $7^{\circ} \mathrm{C}$. All morphological measurements were made within five days of the transfer.

Body tissues were accessed and separated as described previously for scallops (Donovan et al., 2002). Shell length (maximum distance from anterior side to posterior side of the shell), dry shell mass and dry adductor mass were each log-transformed then regressed against log-shell height (maximum distance from dorsal hinge to ventral margin of the shell). Model I regression was used for reasons outlined in Donovan et al. (2002). The resulting slopes were compared to the expected slopes for isometry using the comparison of slopes methods described in Zar (1996).

\section{Drag}

The effect of barnacle and sponge epibionts on the drag coefficient of scallops was measured in drop-tank experiments. The drag coefficient of a macroscopic object moving through a fluid at velocity $\mathrm{v}$ is described by the equation:

$\mathrm{G}_{\mathrm{d}}=2 \mathrm{~F}_{\mathrm{d}} / \rho \mathrm{Sv}^{2}$

where $\mathrm{F}_{\mathrm{d}}$ is force of $\mathrm{drag}, \rho$ is the density of the fluid displaced by the object (1025 $\mathrm{kg} \mathrm{m}^{-3}$ for seawater), and $\mathrm{S}$ is the surface area of the object projecting in the direction of flow. If the object is falling under the force of gravity it will reach a terminal velocity when $F_{d}$ equals the force of gravity less the buoyant force of the fluid. Thus, $\mathrm{F}_{\mathrm{d}}$ can be estimated at terminal velocity by:

$\mathrm{F}_{\mathrm{d}}=\mathrm{mg}-\mathrm{V} \rho \mathrm{g}$

where $\mathrm{m}$ is the mass of the object, $\mathrm{g}$ is gravity, and $\mathrm{V}$ is the volume of the object. Thus, if an object is falling at terminal velocity, $\mathrm{C}_{\mathrm{d}}$ can be estimated from:

$\mathrm{C}_{\mathrm{d}}=2(\mathrm{mg}-\mathrm{V} \rho \mathrm{g}) /\left(\rho \mathrm{Sv}^{2}\right)$

Two experimental groups of scallops were used: those with a large (greater than $1 \mathrm{~cm}$ diameter) barnacle $(\mathrm{N}=10)$ and those that were sponge-encrusted $(\mathrm{N}=8)$. The latter group was included for comparison with previous results (Donovan et al., 2002). Encrusted scallops were first dropped through a column of water and their terminal velocity was measured and used to calculate $\mathrm{C}_{\mathrm{d}}$. Next, the epibiont was removed and $\mathrm{C}_{\mathrm{d}}$ of the unencrusted scallop was determined in the same manner.

To determine terminal velocity, each scallop was videotaped as it fell through a $117 \times 117 \times 92 \mathrm{~cm}$ deep Plexiglas tank, filled to a depth of $66 \mathrm{~cm}$ with seawater $\left(12^{\circ} \mathrm{C}\right)$. A video camera with a timer (accurate to $0.01 \mathrm{~s}$ ) was used and the scallops were dropped next to a meter stick affixed to the side of the tank. To ensure the scallops fell in a straight line with their hinge hindmost (their normal direction of swimming), they were weighted with a $3.5 \mathrm{~g}$ lead sinker attached to a hole drilled in the ventral-most portion of the right valve. The mass of the sinker was added to the mass of the scallop when $\mathrm{C}_{\mathrm{d}}$ was calculated. However, since the area of the sinker was much smaller than the frontal area of the scallop, just the area of the scallop was used in the calculation. Each scallop was dropped three times and the average terminal velocity was determined.

Before treatment scallops were tested, a preliminary experiment was done to ensure that the scallops were reaching terminal velocity in the experimental tank. Three scallops were dropped and each fall recorded on video. The video was analysed frame-by-frame and the distance the scallop had fallen was compared to the time

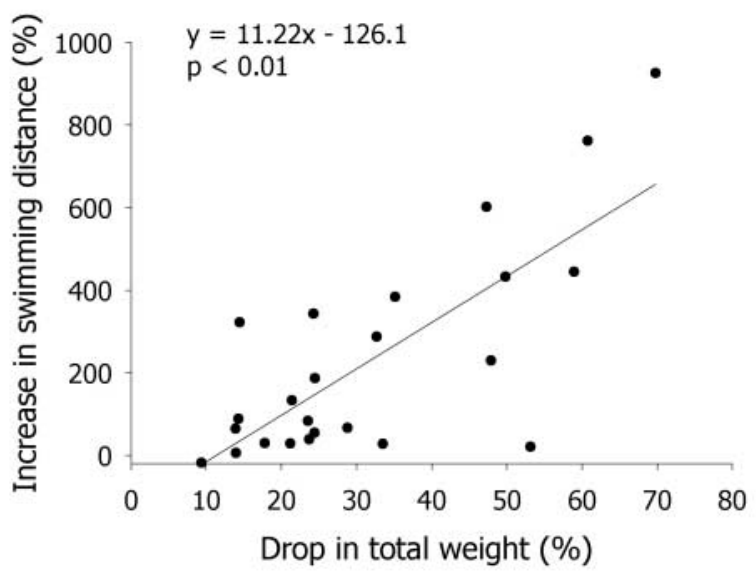

Figure 3. Per cent increase in swimming distance of Chlamys hastata after barnacle removal as a function of barnacle size. 
Table 1. Scaling of swimming related morphometric relationships in barnacle-encrusted scallops Chlamys hastata $(\mathcal{N}=16)$. Data were $\log _{10}$-transformed before a least-squares regression was fit to them. All equations were in the form $\log _{10} \mathrm{Y}=\log _{10} \mathrm{a}+\mathrm{b} \log _{10} \mathrm{X}$, where $\mathrm{b}$ is the slope of the line and $\mathrm{a}$ is the intercept. Slopes were compared to the expected slopes for isometry using methods outlined in Zar (1996).

\begin{tabular}{|c|c|c|c|c|c|c|}
\hline $\log _{10} \Upsilon_{\text {on }} \log _{10} X$ & $\log a$ & $b$ & $\begin{array}{l}\text { Expected slope } \\
\text { for isometry }\end{array}$ & $r^{2}$ & $t$ & $P$ \\
\hline Shell length on shell height & -0.32 & 1.16 & 1 & 0.99 & 6.78 & $<0.001$ \\
\hline Shell mass on shell height & -3.72 & 2.67 & 3 & 0.96 & 2.50 & 0.03 \\
\hline Adductor mass on shell height & -5.39 & 3.07 & 3 & 0.95 & 0.53 & $>0.5$ \\
\hline
\end{tabular}

Table 2. Mean ( \pm SE) epibiont mass and coefficient of drag for scallops encrusted with sponge or barnacles.

\begin{tabular}{|c|c|c|c|c|c|}
\hline & $\begin{array}{l}\text { Epibiont } \\
\text { encrusted }\end{array}$ & $\begin{array}{l}\text { Epibiont } \\
\text { removed }\end{array}$ & $t$ & $P$ & Power \\
\hline \multicolumn{6}{|l|}{ SPONGE } \\
\hline Epibiont mass (g) & $4.6 \pm 1.1$ & & & & \\
\hline $\begin{array}{l}\text { Coefficient of drag } \\
\text { BARNACLE }\end{array}$ & $0.7 \pm 0.1$ & $0.9 \pm 0.2$ & 1.13 & 0.30 & 0.14 \\
\hline Epibiont mass (g) & $7.8 \pm 1.4$ & & & & \\
\hline Coefficient of drag & $1.0 \pm 0.1$ & $0.7 \pm 0.1$ & 2.70 & 0.02 & \\
\hline
\end{tabular}

elapsed for each frame. Terminal velocity was achieved when velocity no longer increased during the fall.

After terminal velocity was determined for each scallop, the size variables needed to calculate $\mathrm{C}_{\mathrm{d}}$ were measured. Scallop volume was determined by water displacement in a 1-1 graduated cylinder and mass was recorded after the scallop was blotted dry. Frontal cross-sectional area was determined by taking a digital picture of the front of the scallop, along with a $1 \mathrm{~cm}^{2}$ reference, and measuring the area with Optimus 6.2 software.

Finally, all epibionts were removed from the scallop. Each scallop was again dropped three times and average terminal velocity without epibiont encrustation was determined. Subsequently, a new volume, mass, and frontal area were determined, allowing $\mathrm{C}_{\mathrm{d}}$ for the unencrusted scallop to be calculated.

To facilitate comparisons with scallops swimming at slower velocities, Reynolds numbers (Re) were estimated for the scallops falling at terminal velocity using the equation (Alexander, 1971):

$\operatorname{Re}=\left(10^{6}\right)(\mathrm{v})(\mathrm{l})$

where $\mathrm{v}$ is velocity in $\mathrm{m} \mathrm{s}^{-1}$ and $\mathrm{l}$ is length in metres.

\section{Aerobic energy consumption}

To estimate aerobic energy used during swimming with and without barnacle encrustation, barnacle-encrusted scallops were randomly assigned to a resting treatment $(\mathrm{N}=10)$ or an active treatment $(\mathrm{N}=9)$. Unencrusted scallops were likewise assigned to a resting treatment $(\mathrm{N}=8)$ or an active treatment $(\mathrm{N}=9)$. Scallops were placed individually into a respirometer $(400 \mathrm{ml}$ or $600 \mathrm{ml}$, depending on the size of the scallop) and induced to swim by touching their mantle with a tubefoot of the sea-star Pycnopodia helianthoides. Oxygen consumption was measured as described in Donovan et al. (2002). Although movement was restricted by respirometer size, all of the scallops were able to lift themselves off the bottom through rapid valve-clapping. All scallops were stimulated until exhausted (determined by refusal to continue valve-clapping) which occurred within two to five minutes.

Differences in oxygen consumption were determined with two-way analysis of variance (ANOVA), using activity state and encrustation as main effects.

\section{Anaerobic energy consumption}

To assess anaerobic energy needed to swim with and without barnacle encrustation, barnacle-encrusted $(\mathrm{N}=8)$ and unencrusted $(\mathrm{N}=8)$ scallops were induced to swim to exhaustion in a $153 \times 69 \mathrm{~cm}$ tank filled with seawater to a depth of $10 \mathrm{~cm}$. Swimming was stimulated by touching the scallop with the sea-star P. helianthoides. When the scallops refused to continue swimming, they were rapidly removed from their shells and the adductor muscles were freezeclamped and stored in liquid nitrogen until analysis. Muscle tissue was also removed from a control group of scallops $(\mathrm{N}=6)$ which were not induced to swim.

To measure anaerobic metabolites, approximately $1 \mathrm{~g}$ of the frozen adductor muscle was homogenized in a test tube with $9 \mathrm{ml}$ of $10 \%$ trichloroacetic acid using an Ultraturrax tissue disrupter. The homogenates were centrifuged at $5000 \mathrm{rpm}$ for $15 \mathrm{~min}$ at $4^{\circ} \mathrm{C}$ and the supernatant pipetted off. Supernatants were neutralized with $5 \mathrm{M} \mathrm{NaOH}$. Octopine levels were determined spectrophotometrically (HP 8452A spectrophotometer) by following the reduction of NAD $^{+}$at $340 \mathrm{~nm}$ (Grieshaber, 1976). Arginine and arginine phosphate levels were measured spectrophotometrically following the method of Gade (1985). Analysis of variance was used to determine if differences occurred between the treatments for each metabolite.

\section{RESULTS}

\section{Swimming behaviour}

Encrusting barnacles strongly affected Chlamys hastata swimming. Swimming time increased significantly after removal of encrusting barnacles (Figure 2), with scallops spending an average of $33 \%$ longer in the water column. Swimming height increased $300 \%$ after barnacle removal and swimming distance doubled. Epibiont mass significantly affected swimming distance. Scallops with heavy 


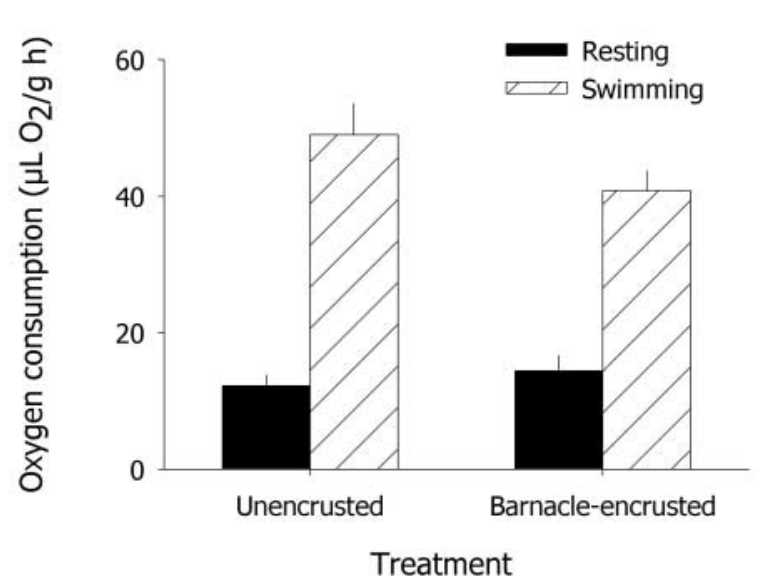

Figure 4. Mean mass specific oxygen consumption of scallops resting and swimming with and without barnacle encrustation. Error bars represent SE. Activity level significantly affected oxygen consumption (see text for two-way ANOVA results) but no effect of barnacle encrustation was detected.

Table 3. Anaerobic metabolites accumulated or used during swimming in unencrusted and barnacle-encrusted scallops. Values are mean $\pm S E$. The ANOVA results are in the text. Superscripts denote means that separated into homogenous subgroups following Tukey's test $(\mathrm{P}<0.05)$.

\begin{tabular}{|c|c|c|c|}
\hline & \multicolumn{3}{|c|}{ Metabolite levels $\left(\mu \mathrm{mol} \mathrm{g}\right.$ muscle $\left.{ }^{-1}\right)$} \\
\hline & $\begin{array}{l}\text { Resting } \\
(\mathrm{N}=6)\end{array}$ & $\begin{array}{l}\text { Unencrusted } \\
(\mathrm{N}=8)\end{array}$ & $\begin{array}{l}\text { Barnacle- } \\
\text { encrusted } \\
(\mathrm{N}=8)\end{array}$ \\
\hline Octopine & $0.6 \pm 0.1^{\mathrm{a}}$ & $1.1 \pm 0.3^{\mathrm{ab}}$ & $1.5 \pm 0.6^{\mathrm{b}}$ \\
\hline Arginine phosphate & $9.3 \pm 1.3^{\mathrm{A}}$ & $4.2 \pm 1.2^{\mathrm{B}}$ & $0.6 \pm 0.4^{\mathrm{C}}$ \\
\hline
\end{tabular}

barnacles generally displayed larger increases in distance after barnacle removal (Figure 3).

Average frequency of valve-clapping decreased significantly after barnacle removal $\left(t_{0.05,7}=4.79, P=0.001\right)$. Mean valve-clapping frequency with encrusting barnacles was

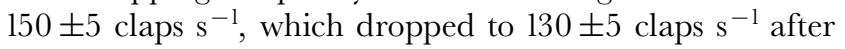
the barnacle removal.

\section{Scallop morphometry}

Barnacle-encrusted scallops displayed two scaling relationships typical of other scallops. Shell length was positively allometric with shell height (causing the shell to become proportionately broader as the scallops increase in size) while shell mass was negatively allometric with shell height (causing the shell to become proportionately lighter) (Table 1). However, adductor muscle mass increased isometrically compared to shell height.

\section{Drag coefficients}

Scallops reached terminal velocity after dropping $5 \mathrm{~cm}$ in the experimental tank. Thus all subsequent velocity measurements were recorded after this distance.
Drag coefficients of barnacle-encrusted scallops decreased significantly after barnacle removal, while no change was detected in $\mathrm{C}_{\mathrm{d}}$ of sponge-encrusted scallops (Table 2). The average terminal velocity $\left(0.55 \mathrm{~m} \mathrm{~s}^{-1}\right)$ yielded a Re of 28,000 for an average scallop length of $5 \mathrm{~cm}$ and the average swimming speed of C. hastata $\left(0.18 \mathrm{~m} \mathrm{~s}^{-1}\right.$; Donovan et al., 2002) yielded a $\operatorname{Re}$ of 9000 . Since $\mathrm{C}_{\mathrm{d}}$ for some shapes (including spheres and cylinders, which scallops marginally resemble) does not change dramatically over this range of $\mathrm{Re}$ (Vogel, 1994), the $\mathrm{C}_{\mathrm{d}} \mathrm{s}$ measured at terminal velocity were considered an estimation of the $\mathrm{C}_{\mathrm{d}} \mathrm{s}$ experienced by scallops in the closed swimming position at $0.18 \mathrm{~m} \mathrm{~s}^{-1}$.

\section{Aerobic energy consumption}

Two-way ANOVA showed that swimming caused a significant increase in oxygen consumption $\left(F_{1,33}=109.6\right.$, $P<0.001$; Figure 4), with both unencrusted and barnacleencrusted scallops increasing aerobic energy expenditure three to four times. However, no significant differences were detected between encrusted and unencrusted scallops $\left(F_{1,33}=0.65, P=0.43\right.$; observed power $\left.=0.12\right)$ nor in the interaction of activity and encrustation $\left(F_{1,33}=2.32, P=0.14\right.$; observed power $=0.31$ ).

\section{Anaerobic energy consumption}

Octopine levels increased significantly with activity, with swimming barnacle-encrusted scallops accumulating the highest levels $\left(F_{2,19}=4.36, P=0.03\right.$; Table 3$)$. Barnacleencrusted scallops accumulated significantly more octopine than resting scallops, and levels found in unencrusted scallops statistically overlapped with the other two treatments (Tukey's; $P<0.05$ ). Arginine phosphate levels decreased significantly with activity $\left(F_{2,19}=16.74, P<0.001\right.$; Table 3$)$, and the three treatments were statistically separated from each other (Tukey's; all $P<0.05$ ).

\section{DISCUSSION}

Barnacle encrustation negatively influenced every aspect of swimming in the scallop Chlamys hastata measured in this study. Some of the most dramatic effects were in swimming ability. When contacted by predatory sea-stars, barnacleencrusted scallops could not swim as far, as high, or as long as unencrusted scallops (Figure 2). These observations have obvious implications for escaping predation since any decrease in time or distance spent swimming makes scallops less able to avoid predators. In fact, the decreases in swimming height and time may be the most serious consequences of barnacle encrustation. The local habitat of C. hastata is subject to strong currents and scallops potentially make use of these currents when swimming. Any decrease in the ability to attain height would hamper the scallop's ability to enter a current and use it to increase swimming distance. Likewise, any decrease in time spent swimming could translate to dramatically decreased distances if currents were used. In this study, swimming time probably decreased because barnacle-encrusted scallops did not swim as high and were more likely to make contact with the bottom of the tank. This in turn caused them to stop swimming. Whether differences in swimming 
time and distance translate into increased scallop mortality due to predation is not known, but laboratory observations suggest that barnacle-encrusted scallops are more often caught and consumed by sea-star predators than are sponge-encrusted scallops (Farren, 2003).

Larger barnacles had a significantly larger effect on swimming distance (Figure 3). Specifically, the greater the weight loss after barnacle removal, the greater the increase in swimming distance of the scallop. This is not surprising given that some barnacles grow so large their host scallops are incapable of swimming. What is surprising is that scallops that were carrying barnacles which weighed more than they did (those that lost more than $50 \%$ of their scallop-barnacle mass) were capable of swimming at all. Maximum epibiont mass was not determined in this study; it would be interesting to determine the maximum mass which can be carried by $C$. hastata and if barnacle location on the valve influences this maximum mass.

Valve-clapping frequency decreased after barnacle removal, indicating that unencrusted scallops needed less power to remain in the water column compared to encrusted scallops (power output is directly related to valve-clapping frequency; Cheng et al., 1996). However, this decrease in clapping frequency is unexpected if swimming scallops are resonant systems as suggested by DeMont (1990). In this case, barnacle removal should increase clapping frequency due to the decrease in mass of the scallop.

The increased need for power of barnacle-encrusted scallops is also evident in the amount of energy expended during swimming. Although aerobic energy expenditure was not significantly different between unencrusted and barnacle-encrusted scallops (Figure 4), barnacle-encrusted scallops used significantly more anaerobic energy while swimming (Table 3). They consumed twice as much arginine phosphate as unencrusted scallops while swimming to exhaustion and octopine levels were elevated as well. Chlamys hastata rely on anaerobic sources for approximately $86 \%$ of the energy expended during escape swimming (Donovan et al., 2002) and this is comparable to other scallop species (Grieshaber \& Gade, 1977; Baldwin \& Opie, 1978; Gade et al., 1978; Grieshaber, 1978; Livingstone et al., 1981). Thus, increases in anaerobic energy requirements represent the bulk of energy expended during swimming.

Part of the effects of barnacles on swimming behaviour and energetics can be explained by the increase in drag coefficient experienced by barnacle-encrusted scallops. Although our measurements represent an estimation of drag in only one phase of the swimming cycle (the closed position in which drag is lowest), it was found that drag coefficients decreased significantly after barnacle removal while no significant decrease was detected after sponge removal (Table 2). Barnacles protruding off the shell increase the surface area of the scallop projecting in the direction of flow. This could increase both pressure and friction drag. It is interesting that sponge encrustation did not increase the drag coefficient of scallops, despite an increase in scallop frontal area. It is possible that the texture of the sponge or the sheet-like nature of the encrustation kept drag from increasing.

Epibionts have been shown to increase drag on other bivalves. Witman \& Suchanek (1984) directly measured drag on mussels encrusted with algal epibionts and found that drag decreased two to six times when algae were removed. They suggested that algae-encrusted mussels would more likely be dislodged during periods of high wave action. They supported this conclusion with observations of stranded mussels, which more often than not had algae encrustation. Interestingly, the epibiont most often observed on stranded mussels (after algae) was balanoid barnacles, suggesting they may also have an effect in this habitat.

Adductor muscle mass of barnacle-encrusted scallops did not exhibit the same scaling relationship with shell height as it does in unencrusted and sponge-encrusted Chlamys hastata (Donovan et al., 2002) and in other scallop species (Gould, 1971). Adductor muscle mass of most scallops increases more than would be expected by isometry. This has been explained by the need to generate proportionately more power as the scallop grows larger, due to its increasing mass (Gould, 1971). Decreased muscle growth in barnacle-encrusted scallops may indicate they are not spontaneously swimming as often as other scallops, possibly due to the increased energy demands they incur when they are forced to swim. This is supported by Kleinman et al. (1996) who found that Placopecten magellanicus induced to swim more frequently had significantly higher adductor condition indices (dry adductor muscle mass as a percentage of dry body tissue mass) than a control treatment. However, they found no significant difference between shell heights of the two treatments. Similarly, the shells of barnacle-encrusted $C$. hastata showed scaling relationships typical of sponge-encrusted and unencrusted $C$. hastata, and similar to other scallop species. Specifically, shell mass increased proportionately less than expected compared to shell height, and shell length increased proportionately more than expected. Both of these morphological characteristics are thought to help scallops swim as they get larger by reducing drag and decreasing the amount of lift that must be generated (Gould, 1971).

Barnacles have substantial impacts on the swimming behaviour and energetics of Chlamys hastata and this may extend to other epibionts as well. It is possible that scallops could obtain some benefit from barnacle encrustation, such as visual or tactile camouflage from predators. However, it is unlikely that such benefits would outweigh the obviously negative impact that barnacles have on swimming ability. It is also unclear what benefits barnacles might obtain from the association, beyond a place to settle. Without further information it is difficult to classify this relationship, but it is certainly not a mutualism as is the scallopsponge association.

We wish to thank the faculty and staff at Shannon Point Marine Center for research space and support. Gene McKeen, Gisele Muller-Parker, and Nathan Schwarck helped immensely with scallop collection. Fiona Donovan assisted with the morphological measurements. Parts of this work were supported by a National Science Foundation grant OCE 9731144 (Research Experience for Undergraduates).

\section{REFERENCES}

Alexander, R.McN., 1971. Functional design in fishes. London: Hutchinson Publishing Group Ltd. 
Baldwin, J. \& Opie, A.M., 1978. On the pole of octopine dehydrogenase in the adductor muscles of bivalve molluscs. Comparative Biochemistry and Physiology, 61B, 85-92.

Bloom, S.A., 1975. The motile escape response of a sessile prey: a sponge-scallop mutualism. Fournal of Experimental Marine Biology and Ecology, 179, 311-321.

Burns, D.O. \& Bingham, B.L., 2002. Epibiotic sponges on the scallops Chlamys hastata and Chlamys rubida: increased survival in a high-sediment environment. Fournal of the Marine Biological Association of the United Kingdom, 82, 4098-4104.

Cheng, J.-Y., Davison, I.G. \& DeMont, M.E., 1996. Dynamics and energetics of scallop locomotion. Fournal of Experimental Biology, 199, 1931-1946.

Cheng, J.-Y. \& DeMont, M.E., 1996a. Hydrodynamics of scallop locomotion: unsteady fluid forces on clapping shells. Fournal of Fluid Mechanics, 317, 73-90.

Cheng, J.-Y. \& DeMont, M.E., 1996b. Jet-propelled swimming in scallops: swimming mechanics and ontogenic scaling. Canadian Journal of Zoology, 74, 1734-1748.

Dadswell, M.J. \& Weihs, D., 1990. Size-related hydrodynamic characteristics of the giant scallop Placopecten magellanicus (Bivalvia: Pectinidae). Canadian Fournal of Zoology, 68, 778-785.

DeMont, M.E., 1990. Tuned oscillations in the swimming scallop Pecten maximus. Canadian Fournal of Zoology, 68, 786-791.

Donovan, D.A., Bingham, B.L., Farren, H.M., Gallardo, R. \& Vigilant, V.L., 2002. Effects of sponge encrustation on the swimming behaviour, energetics and morphometry of the scallop Chlamys hastata. Journal of the Marine Biological Association of the United Kingdom, 82, 469-476.

Farren, H.M., 2003. Sponge epibionts protect the scallop Chlamys hastata from barnacle encrustation and seastar predation. MS thesis, Western Washington University, USA.

Forester, A.J., 1979. The association between the sponge Halichondria panicea (Pallas) and scallop Chlamys varia (L.): a commensal protective mutualism. Fournal of Experimental Marine Biology and Ecology, 36, 1-10.

Gade, G., 1985. Arginine and arginine phosphate. In Methods of enzymatic analysis, vol. VIII (ed. H.U. Bergmeyer), pp. 424-431. Weinheim: Verlag Chemie.

Gade, G., Weeda, E. \& Gabbott, P.A., 1978. Changes in the level of octopine during the escape responses of the scallop, Pecten maximus (L.). Journal of Comparative Physiology, 124B, 121-127.

Gonzalez, S.A., Stotz, W.B. \& Aguilar, M., 2001. Stranding of scallops related to epiphytic seaweeds on the coast of northern Chile. Fournal of Shellfish Research, 20, 85-88.

Gould, S.J., 1971. Muscular mechanics and the ontogeny of swimming in scallops. Paleontology, 14, 61-94.

Grieshaber, M., 1976. An enzymatic method for the estimation of octopine. Analytical Biochemistry, 74, 600-603.

Grieshaber, M., 1978. Breakdown and formation of high-energy phosphates and octopine in the adductor muscle of the scallop, Chlamys opercularis (L.), during escape swimming and recovery. Fournal of Comparative Physiology, 126B, 269-276.
Grieshaber, M. \& Gade, G., 1977. Energy supply and the function of octopine in the adductor muscle of the scallop, Pecten jacobaeus (Lamarck). Comparative Biochemistry and Physiology, 58B, 249-252.

Hamilton, P.V. \& Koch, K.M., 1996. Orientation toward natural and artificial grassbeds by swimming bay scallops, Argopecten irradians (Lamarck, 1819). Fournal of Experimental Marine Biology and Ecology, 199, 79-88.

Kleinman, S., Hatcher, B.G. \& Scheibling, R.E., 1996. Growth and content of energy reserves in juvenile sea scallops, Placopecten magellanicus, as a function of swimming frequency and water temperature in the laboratory. Marine Biology, 124, 629-635.

Livingstone, D.R., deZwaan, A. \& Thompson, R.J., 1981. Aerobic metabolism, octopine production and phosphoarginine as sources of energy in the phasic and catch adductor muscles of the giant scallop Plactopecten magellanicus during swimming and the subsequent recovery period. Comparative Biochemistry and Physiology, 70B, 35-44.

Millward, A. \& Whyte, M.A., 1992. The hydrodynamic characteristics of six scallops of the super family Pectinacea, class Bivalvia. Fournal of Zoology, 227, 547-566.

Moore, J.D. \& Trueman, E.R., 1971. Swimming of the scallop, Chlamys opercularis (L.). Fournal of Experimental Marine Biology and Ecology, 6, 179-185.

Moore, J.K. \& Marshall, N., 1967. An analysis of the movements of the bat scallop, Aequipecten irradians, in a shallow estuary. Proceedings of the National Shellfish Association, 57, 77-82.

Morton, B., 1980. Swimming in Amusium pleuronectes (Bivalvia: Pectinidae). Fournal of Zoology, 190, 375-404.

Peterson, C.H., Ambrose, W.G. Jr \& Hunt, J.H., 1982. A field test of the swimming response of the bay scallop (Argopecten irradians) to changing biological factors. Bulletin of Marine Science, 32, 939-944.

Pitcher, C.R. \& Butler, A.J., 1987. Predation by asteroids, escape response, and morphometrics of scallops with epizoic sponges. Fournal of Experimental Marine Biology and Ecology, 112, 233-249.

Stephens, P.J. \& Boyle, P.R., 1978. Escape responses of the queen Chlamys opercularis (L.) (Mollusca: Bivalvia). Marine Behaviour and Physiology, 5, 103-113.

Thomas, G.E. \& Gruffydd, L.D., 1971. The types of escape reactions elicited by the scallop Pecten maximus by selected seastar species. Marine Biology, 10, 87-93.

Vogel, S., 1994. Life in moving fluids, 2nd edn. Princeton, New Jersey: Princeton University Press.

Witman, J.D. \& Suchanek, T.H., 1984. Mussels in flow: drag and dislodgment by epizoans. Marine Ecology Progress Series, 16, 259-268.

Zar, J.H., 1996. Biostatistical analysis, 3rd edn. New Jersey: Prentice Hall. 